\title{
La cirugía estética como relación de consumo*
}

\author{
Rafaela Ester Sayas Contreras" \\ Juan Sebastián Mercado Verbel"**
}

Recibido: 29 de junio de 2016 • Aprobado: 30 de octubre de 2017

https://doi.org/10.22395/ojum.v17n33a8

\section{RESUMEN}

La sociedad capitalista determina la creación de necesidades expresadas en el acceso a nuevos bienes y servicios que distan del consumo de subsistencia, lo que promueve la compra de productos simbólicos que proporcionan experiencias que despliegan satisfactores distintos al consumo racional. La proliferación de la cirugía plástica merece un análisis especial, pues en el año 2016, Colombia fue el tercer país latinoamericano -solo precedido por Brasil y México, respectivamente- donde más se realizaron procedimientos estéticos quirúrgicos, al punto de promoverse como un destino para el "turismo de bisturí" de forma institucional. Este artículo pretende caracterizar a la cirugía estética como producto de consumo, en el marco de una interpretación conforme al principio pro consumidor, con las consecuencias jurídicas de tal postura. Para ello, se analizará la relación jurídica surgida entre el cirujano estético y su paciente, para luego verificar si esta se enmarca dentro del estatuto del consumidor, y por último se identificarán las consecuencias prácticas de incluir las obligaciones de este contrato dentro del derecho del consumidor, y así dilucidar la responsabilidad médica en virtud de daños causados a un paciente por este tipo de procedimientos.

Palabras clave: Cirugía estética, responsabilidad médica, relación de consumo, obligaciones de medio, obligaciones de resultado.

Informe de avance de la investigación realizada en el marco del programa Colciencias Fortalecimiento de las capacidades regionales y locales de los consumidores: promoción de las competencias establecidas en el nuevo Estatuto del consumidor, Proyecto Cartagena. 2015-2016.

** Abogada de la Universidad de Cartagena (Colombia). Especialización en Derecho Financiero del Colegio Mayor Nuestra Señora del Rosario (Colombia). Especialización en Conciliación y Resolución de Conflictos de la Universidad de Cartagena (Colombia). Magíster en Derecho de la Universidad Nacional de Colombia. Doctora en Sociología de la Universidad de Belgrano (Buenos Aires, Argentina). Docente de la Universidad de Cartagena y de la Maestría en Derecho de la Universidad de Medellín. Directora del grupo de investigación Conflicto y Sociedad, categoría A de Colciencias (Colombia). Correo electrónico: rafaelaester@gmail.com . Perfil Orcid: https://orcid.org/0000-0001-9342-3907

** Abogado de la Universidad de Cartagena (Colombia). Semillerista del grupo de investigación Conflicto y Sociedad, categoría A de Colciencias (Colombia). Correo electrónico: jmercadov@unicartagena.edu.co.Perfil Orcid: https://orcid.org/0000-0003-4809-3480 


\title{
Cosmetic Surgery as a Consuming Relationship
}

\begin{abstract}
Capitalist society determines the creation of needs expressed in the access to new goods and services that are far from subsistence consumption, which promotes the purchase of symbolic products providing experiences that deploy satisfaction other than rational consumption. The proliferation of plastic surgery deserves a special analysis, since in 2016, Colombia was the third Latin American country -only preceded by Brazil and Mexico, respectively-where more cosmetic surgical procedures were performed, to the point of being promoted as a destination for "scalpel tourism" in an institutional manner. This paper aims to characterize cosmetic surgery as a consuming product, within the framework of an interpretation in accordance with the pro-consumer's principle, with the legal consequences of such a position. To this end, the legal relationship between the cosmetic surgeon and his or her patient will be analyzed, in order to verify whether this is within the framework of the consumer's status, and finally, the practical consequences of including the obligations of this contract within the consumer's law will be identified, in order to elucidate the medical responsibility for damages caused to a patient by this type of procedure.
\end{abstract}

Keywords: Cosmetic surgery; medical responsibility; consumption ratio; environmental obligations; performance obligations.

\section{A cirurgia estética como relação de consumo}

\section{RESUMO}

A sociedade capitalista determina a criação de necessidades expressas no acesso a novos bens e serviços que se distanciam do consumo de subsistência, o que promove a compra de produtos simbólicos que proporcionam experiências que desdobram satisfatores diferentes ao consumo racional. A proliferação da cirurgia plástica merece uma análise especial, já que, no ano de 2016, a Colômbia foi o terceiro país latino-americano — precedido apenas pelo Brasil e pelo México, respectivamente- onde mais se realizou procedimentos estéticos cirúrgicos, a ponto de promover-se como um destino para o "turismo do bisturi" de forma institucional. Este artigo pretende caracterizar a cirurgia estética como produto de consumo, no âmbito de uma interpretação conforme o princípio pro consumidor, com as consequências jurídicas de tal postura. Para isso, a relação jurídica que surge entre o cirurgião estético e seu paciente será analisada para depois verificar se esta se encaixa no estatuto do consumidor; por último, serão identificadas as consequências práticas de incluir as obrigações desse contrato dentro do direito do consumidor e, assim, elucidar a responsabilidade médica em virtude dos danos causados a um paciente por esse tipo de procedimento.

Palavras-chave: Cirurgia estética; obrigações de meio; obrigações de resultado; relação de consumo; responsabilidade médica. 


\section{INTRODUCCIÓN}

Colombia es el noveno país en donde más se realizaron procedimientos estéticos quirúrgicos en el año 2016, con un total de 288.443 según las cifras de la Sociedad Internacional de Cirugía Plástica Estética (ISAPS, por sus siglas en inglés). Un análisis dogmático de la figura contractual utilizada para este tipo de relaciones es pertinente para comprender qué obligaciones tienen, tanto médico como paciente, cuando pactan practicar este tipo de procedimientos en la medida que la cantidad de servicios médico-estéticos demandados en Colombia es altísima.

A pesar de que el mercado ha banalizado esta clase de procedimientos, en algunos de los casos se juega la salud y calidad de vida de los pacientes. Debido a esto, este trabajo pretende que los servicios médicos estéticos sean analizados desde la categoría conceptual "relación de consumo", que fungirá como dispositivo de análisis de una realidad social que implica el ofrecimiento de estos servicios, para así determinar el contenido de las obligaciones de las partes, beneficiándose la más débil en la relación contractual.

Como marco fáctico de la situación, se advirtió que Colombia, en el contexto de los países latinoamericanos, es el tercer país en donde más se realizan procedimientos quirúrgicos-estéticos solo superado por Brasil y México, e inclusive desde el Ministerio de Comercio, Industria y Turismo se promueve la prestación de este tipo de servicios como oportunidad de negocio en Colombia (Proexport, 2013).
En ese orden de ideas, los servicios médicos son ofrecidos desde parámetros de mercado que buscan crear una necesidad en el consumidor a través de técnicas de mercadeo que desbordan la relación clásica médico paciente. Así las cosas, "la práctica de la cirugía estética se inscribe desde un sistema general de mercado impulsado por la globalización y el capitalismo" (Herrera , 2012, p. 9).

El tratamiento jurídico dado en el país a estas relaciones jurídicas por jueces e instituciones complica la situación, pues las interpretaciones no son unívocas; en ocasiones se trata a los servicios médicos estéticos desde parámetros de consumo, y otras veces como una relación ordinaria civil, lo cual genera falta de certeza en el marco obligacional, particularmente para los pacientes, quienes son la parte débil de esa relación, por las asimetrías que comporta el acceso al conocimiento técnico.

La Corte Suprema de Justicia se ha manifestado sobre el particular, específicamente a los servicios de salud, y dijo que la relación entre las instituciones prestadoras de salud y los pacientes es de consumo, en la medida que,

[E]s incuestionable que la contratación masiva afectó, igualmente, la prestación del servicio de salud y produjo notables modificaciones en la relación médico paciente hasta entonces existente, que de índole individual y personalizada pasó a ser no solamente extensa, sino también compleja en cuanto está a cargo de organi- 
zaciones con carácter empresarial (Corte Suprema de Justicia, Sentencia de 22 de julio de 2010. M. P. Pedro Octavio Munar Cadena).

En ese orden de ideas, estableció que la prestación de servicios médicos se enmarca dentro de una relación de consumo, y los jueces deben interpretarlos según el principio pro consumatore; inclusive trajo a colación las directrices de Naciones Unidas sobre Consumo, plasmadas en la Resolución 39/248 que sugirió una política enérgica para la protección a los consumidores y usuarios en el marco de la prestación de servicios hospitalarios.

Dicha afirmación reforzó la postura de la responsabilidad en el ofrecimiento de los servicios de salud, la cual no solo concierne al acto médico en sentido estricto, sino a la responsabilidad de variados tipo de servicios que pueden abarcar asistencia sanitaria, paramédica, y servicios de hospitalización, entre otros.

La sentencia citada es una decisión relacionada con la responsabilidad médica antes de la expedición del Nuevo Estatuto del Consumidor (Ley 1480/2011), por lo cual el marco normativo y el contexto interpretativo eran diferentes, pese a que se reconocía la asimetría contractual de los pacientes-consumidores.

Por otro lado, la Superintendencia de Industria y Comercio (SIC) rindió un concepto, en virtud de una consulta ciudadana relacionada con la aplicación del Estatuto del Consumidor a una clínica de cirugías plásticas, en el cual recalcó el carácter supletivo de la Ley 1480 de 2011, es decir, que ha de aplicarse en ausencia de regímenes especiales. Sobre el particular sostuvo que, "para el caso de las clínicas estéticas no se cuenta con disposiciones especiales en relación con los derechos de los consumidores, por lo cual resulta aplicable de manera principal la Ley 1480 de 2011" (SIC, 2013).

Los negocios jurídicos relativos a los procedimientos médico-estéticos se encuadran en un tipo de relación especial que desborda las relaciones contractuales clásicas con el médico cirujano. Esta situación implica un redimensionamiento de las obligaciones contraídas, y en ese mismo sentido, las respuestas del ordenamiento jurídico cuando no se dan los resultados estéticos esperados.

Para efectos de este trabajo, se entiende como relación de consumo aquella estimulada por el mercado que se traba entre un fabricante o proveedor de un producto (bien o servicio) y una persona natural o jurídica para la satisfacción de una necesidad propia (no comercial). La ley colombiana no definió qué es una relación de consumo, pero sí estableció quién es un consumidor o usuario en el numeral 3. del artículo 5 del estatuto pertinente, de esta forma:

Toda persona, natural o jurídica que, como destinatario final, adquiera, disfrute o utilice un determinado producto, cualquiera que sea su naturaleza, para la satisfacción de una necesidad propia, privada, familiar o do- 
méstica y empresarial, cuando no esté ligada intrínsecamente a su actividad económica.

Cabe rescatar de esta definición que la calidad de "destinatario final" hace re ferencia a que el beneficiario adquiera el bien o servicio para la satisfacción de una necesidad propia y no con fines comerciales.

Las legislaciones de Brasil, Uruguay y Argentina incluyen expresamente en la definición de consumidor a la relación de consumo; inclusive la de Argentina alude a los consumidores en los mismos términos de la legislación colombiana, pero adicionalmente menciona en el parágrafo 1.que,

\begin{abstract}
Se considera así mismo consumidor o usuario a quién, sin ser parte de una relación de consumo, como consecuencia o en ocasión de ella adquiere o utiliza bienes o servicios como destinatario final, en beneficio propio o de su grupo familiar o social, y a quien de cualquier manera está expuesto a una relación de consumo (L.24.240/2008).
\end{abstract}

Por ello, es relevante tomar en consideración el ofrecimiento de bienes y servicios de manera intencionada, para estimular la demanda desde los parámetros de economía de mercado y resaltar al consumidor como el más frágil de la cadena de consumo. En el mismo sentido lo expresa Villalba (2009), aludiendo a que "la relación de consumo es un vínculo jurídico obligacional de carácter especial propio de las relaciones económicas capitalistas de la vida moderna, que se puede configurar en la fases precontractual, contractual o extracontractual, y que además rompe con los esquemas tradicionales del derecho privado" (p. 92).

El escenario jurídico y las herramientas normativas disponibles no siempre ofrecen soluciones unívocas, lo que evidencia que los consumidores de servicios médicos estéticos podrán estar desprotegidos frente a ciertas prácticas de los agentes del mercado. Por ello, para determinar los alcances y limitaciones de la figura, se plantea la siguiente pregunta: ¿De qué manera el ofrecimiento de servicios de cirugía médica estética podría ser caracterizado como relación de consumo? En esa medida ¿Cuáles serían los efectos prácticos de la misma? Responder estos cuestionamientos permitirá lograr el cometido de esta investigación, el cual es clarificar el contenido obligacional de la relación del cirujano estético con su paciente y los efectos de las mismas para cada una de las partes contractuales.

\section{METODOLOGÍA}

La investigación se desarrolla desde los parámetros de la investigación cualitativa, jurídico-dogmática, descriptiva, con fundamento en la recopilación y análisis de información secundaria. Para tales efectos, se procedió al relevamiento, clasificación y análisis de información condensada en normas, sentencias de la Corte Suprema de Justicia y textos especializados. Se utilizó como dispositivo de análisis la categoría transversal de "relación de consumo", con lo cual 
se exploraron alternativas hermenéuticas distintas a las existentes en el tema en cuestión.

Así las cosas, este trabajo se ha divido de la siguiente manera: en primer lugar se analizará la naturaleza jurídica del contrato de servicios médicos y de servicios médicos estéticos; luego, en este contexto, la postura de la Corte Suprema de justicia en torno a la responsabilidad médica, para luego proceder a la caracterización de la cirugía estética como relación de consumo y de esa manera determinar los alcances jurídicos e interpretativos de esa postura, brindando posibles soluciones en el derecho colombiano a las problemáticas derivadas de este tipo de relaciones desde la perspectiva de protección al consumidor.

\section{EL CONTRATO DE PRESTACIÓN DE SERVICIOS MÉDICOS Y EL DE SERVICIOS MÉDICOS ESTÉTICOS}

En Colombia, la atención en salud se entiende como un servicio público cuya prestación está organizada y reglamentada por el Estado, según lo establecido en el artículo 49 de la Constitución Política. Por tanto, la prestación de este servicio como regla general tiene una regulación estricta, cuyo incumplimiento tiene consecuencias de carácter sancionatorio.

A pesar de lo anterior, el Sistema General de Seguridad Social en Salud (SGSS) no es incompatible con el ofrecimiento de servicios médicos particulares de los profesionales en el ejercicio de esta profesión liberal. Este aspecto se resalta, porque la prestación de servicios médico-estéticos no se encuentra plenamente regulada en las normas de orden público, sino que tiene su fundamento en la autonomía de la voluntad de los contratantes. Precisamente, es esta la que determina el contenido obligacional del contrato médico, lo que tiene implicaciones diversas en el contenido del convenio y especialmente en la naturaleza de las obligaciones emanadas del mismo.

Por lo antedicho, en este acápite se analizarán los elementos del contrato médico de manera general, y de manera particular, del contrato de medicina estética, pues, el objeto contractual del último implica una obligación de embellecimiento con el paciente-consumidor, mientras que en la relación tradicional "el objeto de la obligación asumida por el galeno son las prestaciones de conductas profesionales tendientes a la curación; la obligación del paciente es el pago de estos servicios" (Lorenzetti, 1997, p. 317). De ello se desprende que las obligaciones de una y otra relación no pueden tener consecuencias homogéneas y se hace necesaria la determinación del caso concreto analizado.

En ese orden de ideas, es menester clarificar la relación que existe entre cirugía plástica y cirugía estética, la cual es de género a especie, siendo la cirugía estética una especie dentro de la categoría de la cirugía plástica. Existen dos clases: (i) la cirugía reparadora que persigue corregir defectos congénitos o adquiridos, como por ejemplo las malformaciones al nacer o las quemaduras y grandes cicatrices; y (ii) 
la cirugía estética que tiene como único objetivo embellecer al paciente (Jaramillo, 2011, p. 374).

En el ordenamiento jurídico vigente en Colombia (Ley 100 de 1993 y los decretos 1570 de 1993, 1485 y 1486 de 1994; Ley 23 de 1981) existen varias formas o tipologías de crear vínculos obligacionales entre un médico y un paciente según si se hace dentro del sistema de salud o como contrato independiente. A continuación, se expone brevemente el tipo de relaciones contractuales que surgen de la relación del paciente con su médico, las cuales se expresan en relaciones directas o relaciones indirectas (intermediarios del sistema de salud).

En la primera de ellas -las directas- el médico y su paciente, por sus propios medios, entablan una relación contractual sin intermediarios. Las obligaciones que nacen del vínculo devienen únicamente de lo que las partes establezcan en el marco de la confianza que el paciente deposita en el galeno, por su prestancia social o la publicidad a la cual haya tenido acceso, consecuencia de la difusión que el prestador hiciera de los servicios ofertados, como, por ejemplo, el ofrecimiento de servicios médicos por parte de especialistas que prestan un servicio muy concreto (nefrólogos, psiquiatras, neurólogos, etc.); empero, con la aparición de las empresas de medicina pre-pagada la relación directa médico-paciente se ha reducido y los pacientes (usuarios) se han acogido a los servicios ofertados por los portafolios de este tipo de empresas.
En este tipo de contratos, la responsabilidad de la prestación del servicio, recae única y exclusivamente en el médico, puesto que el paciente acudió directamente a él en virtud de su idoneidad y es quien tiene la responsabilidad directa de la ejecución del contrato. Sin embargo, las normas relativas a la calidad, seguridad e higiene en la prestación del servicio son las contenidas en el SGSSS, pero el contenido prestacional (objeto del contrato) se enmarca en el derecho privado y las reglas de la lex artis ad hoc. Los negocios jurídicos voluntariamente celebrados entre el médico y el paciente se encuentran expresamente autorizados por el numeral primero del artículo 5 de la Ley 23 de 1981, relacionado con la "decisión voluntaria y espontánea de ambas partes" que traba la relación médico-paciente.

En cuanto a las segundas -las indirectas- se configuran con intermediarios o actores de Sistema de Salud, como las Entidades Prestadoras de Salud (EPS), las Instituciones Prestadoras de Salud (IPS) y las instituciones de medicina pre-pagada. Así las cosas, la relación médico asistencial, por regla general, se desarrolla en el marco de la regulación que para el efecto expide el Ministerio del ramo, con fundamento en la Ley Estatutaria de Salud. Los entes intermediarios principales son las EPS, personas jurídicas que se encargan del registro de los afiliados (cotizantes y beneficiarios) y del recaudo del dinero por concepto de aportes al sistema. En este contexto, los profesionales del servicio de salud son contratados directamente por las EPS o por las IPS, y prestan el servicio al paciente, pero únicamente en virtud 
de la relación entre este y la EPS. Por lo tanto, en esta modalidad, el vínculo del médico con el paciente no es libre y quien garantiza las condiciones de la prestación es la EPS, mientras que el médico es un ejecutor de las obligaciones contraídas por la entidad prestadora.

Por otro lado, la elección de una institución de medicina pre-pagada, implica para el paciente, una cobertura adicional con mayores estándares de calidad que los planes obligatorios de salud brindados por las EPS. Estos servicios se venden a los usuarios del sistema, en el marco de una relación contractual privada, cuyo parámetro delimitador es la autonomía de la voluntad. Estos contratos son de adhesión, pues cada prestador ofrece un portafolio de servicios y el usuario decide si acogerse o no a las condiciones ofertadas. La Corte Constitucional indicó al respecto que:

En relación a los elementos y características del contrato de medicina prepagada, en sentencia T-650 de agosto 17 de 2007 M. P, Clara Inés Vargas Hernández, se estableció que "reúne las características de ser bilateral, oneroso, aleatorio, principal, consensual y de ejecución sucesiva en los términos del Código Civil y surge al mundo jurídico como un contrato de adhesión, según el cual las partes contratantes se obligan mutuamente a través de cláusulas y condiciones que no son discutidas libre y previamente, sino preestablecidas por una de las partes en los términos aprobados por el organismo de intervención estatal y sobre las cuales la otra expresa su aceptación y adherencia o su rechazo absoluto".[...] estos contratos se rigen por las normas de derecho privado, toda vez que el acuerdo de voluntades genera derechos y obligaciones para las partes, y en ese sentido, cada contratante debe cumplir con todo lo establecido [...] (Corte Constitucional, Sentencia T-661 de 2009, M. P. Nilson Pinilla Pinilla).

Siendo más específicos y ubicándonos en el contexto planteado para este trabajo, es relevante considerar la relación directa médico-paciente, debido a que los servicios de cirugía estética son ofrecidos por fuera del SGSSS y es el paciente quien acude directamente al galeno para que le preste el servicio. Sin embargo, cabría preguntarse, si el ofrecimiento de servicios médicos estéticos desde parámetros empresariales desborda la dinámica de la relación médico paciente civil y desemboca en una relación de consumo. Así la cosas, hay que determinar si este tipo de servicios deben ser analizados, bien desde los parámetros de la contratación civil en un marco de autonomía de la voluntad o desde la lógica del mercado, aspecto que implicaría una protección reforzada del paciente consumidor. Para ser más precisos, el contrato de cirugía estética, atendiendo el contexto normativo colombiano, es considerado un contrato más, que debe cumplir los requisitos de existencia y de validez de cualquier otro negocio jurídico y que según su naturaleza se puede clasificar como:

a. Consensual: puesto que se perfecciona con el acuerdo de las partes de 
celebrarlo, es decir, cuando el paciente escoge al galeno que considera idóneo para que practique el procedimiento quirúrgico embellecedor que cree necesitar, el profesional ofrece un precio para el servicio y el paciente acepta, se perfecciona el pacto.

b. Bilateral: las partes tienen obligaciones correlativas, el médico debe cumplir con todo lo establecido por la lex artis ad hoc para el procedimiento quirúrgico que se pactó, el paciente debe pagar los honorarios y tanto médico como paciente se comprometen a llevar a cabo lo requerido en el posoperatorio, así como las demás obligaciones convenidas en el negocio jurídico particular.

c. Conmutativo: las prestaciones del negocio jurídico se encuentran plenamente establecidas ab initio de la relación contractual y entre ellas existe un parámetro de equivalencia entre lo que se da y lo que se recibe; no existe ningún riesgo inherente a la estructura jurídica del contrato (Castillo Freyre y Céspedes Susuki, s. f.), pues los honorarios y el procedimiento quirúrgico a realizar se pactaron desde el comienzo. Quienes consideran que el contrato médico es aleatorio olvidan que "... la prestación a la que se obliga el galeno consiste en una obligación de hacer, poniendo sus conocimientos, medios y diligencia a fin de procurar la curación" (Lorenzetti, 1997); por tanto, no es la curación per se el objeto del contrato, que es en sí misma aleatoria, sino que el médico cumple con los procedimientos establecidos para la práctica de la respectiva cirugía acordada o lex artis ad hoc. Esta característica se hará relevante a la hora de examinar la categoría dogmática de las obligaciones de medio y de resultado, las cuales serán determinantes para el análisis de la responsabilidad por daños causados en cumplimiento del objeto contractual.

d. Oneroso: en el caso de la cirugía plástica estética, se pactan unos honorarios como contraprestación directa al servicio embellecedor ejecutado por el galeno en virtud del contrato de prestación de servicios.

e. Profesional: una de las partes -el cirujano estético- posee un conocimiento experto, un exceso de información respecto a su contraparte, de lo que surge una relación asimétrica, en donde una parte se encuentra a merced de la otra, pues no puede discutir los términos precisos de la prestación; esto porque al ser lego en la materia médica, se ve obligado a aceptar las condiciones de prestación que el médico ofrece; por ello, y en virtud de ser Colombia un Estado social de derecho, el sistema jurídico debe llevar a cabo acciones positivas para nivelar la relación.

\section{LA RESPONSABILIDAD MÉDICA EN LA JURISPRUDENCIA DE LA CORTE SUPREMA DE JUSTICIA}

En Colombia, la responsabilidad médica tiene una línea jurisprudencial que data de inicios del XX, así como una decan- 
tada doctrina cuyo basamento se ancla en la prueba de la culpa del galeno, que está a cargo del demandante (Jaramillo, 2010, p. 395).

Ahora bien, para establecer un orden en este acápite, se efectuará un breve análisis de los pronunciamientos de la Corte, relativos a la posición de la Corporación en torno de la responsabilidad médica y "médica estética", para luego analizar alternativas garantistas que ofrece el ordenamiento jurídico en desarrollo de disposiciones constitucionales, de la mano de interpretaciones más actuales en el marco de las normas de protección al consumidor.

Si bien desde la década de los años 40, la Corte determinó que la imputabilidad en los casos de responsabilidad médica debía analizarse según el régimen subjetivo, en algunas oportunidades la Corte predicó la responsabilidad médica con fundamento en el artículo 2356 del Código Civil, por tratarse de actividades peligrosas y analizó la responsabilidad conforme a la presunción de culpa, (14 de octubre de 1959 -G. J. N. ${ }^{\circ} 2217$, pp. 759 y ss.; Sentencia del 14 de marzo de 1942).

A pesar de la excepción anterior, es casi invariable la tesis que considera que la responsabilidad médica se maneja desde la perspectiva de la culpa probada, porque si bien comporta riesgos, estos son inferiores a las consecuencias de la no prestación del servicio y persigue fines importantes para la sociedad; de igual manera aceptar este supuesto haría impracticable el ejercicio la medicina.
Empero, a partir del análisis de las obligaciones de medio y de resultado concluyó que: "Puede haber casos en que el médico asume una obligación de resultado, como la intervención quirúrgica en una operación de fines estéticos" (Corte Suprema de Justicia, Sentencia de 30 de enero de 2001, M. P. José Fernando Ramírez Gómez).

En menester señalar que en la relación del médico con su paciente, la obligación prestacional del médico es de medio y para acreditar su responsabilidad es necesario tener certeza de la culpa y que esta sea grave como regla general, de tal forma fue expuesto en la sentencia de 05 de marzo de 1940 de la Corte Suprema de Justicia, (G. J. N.o 1953, p. 119, citado por Corte Suprema de Justicia, Sentencia del 30 de agosto de 2013, M. P. Ruth Marina Díaz Rueda).

Si bien, el parámetro obligacional antedicho aplica generalmente a la responsabilidad médica, según la jurisprudencia, cada contrato de prestación de servicios médicos debe ser individualmente examinado para poder determinar la responsabilidad del galeno, porque "es este contrato específico el que va a indicar los deberes jurídicos que hubo de asumir el médico, y por contera el comportamiento de la carga de la prueba en torno a los elementos que configuran su responsabilidad y particularmente de la culpa" (Corte Suprema de Justicia, Sentencia de 30 de enero de 2001, M. P. José Fernando Ramírez Gómez).

Quiere decir lo anterior que debe valorarse el acuerdo al que llegaron las partes 
contratantes para poder establecer el criterio de imputabilidad de responsabilidad aplicable en cada caso, lo cual tiene implicaciones serias, porque en un caso y en el otro -obligaciones de medio y de resultado-se altera la carga de la prueba respecto al elemento de la culpa. Al respecto, la Corte Suprema de Justicia considera que las partes están en absoluta libertad de establecer si la obligación del médico es de medio o de resultado, pues no existe ninguna restricción al respecto, por lo que concluyó que:

[E]n desarrollo del principio de autonomía privada pueden presentarse casos, valga precisarlo, no solamente en el campo de la cirugía plástica con fines estéticos o de embellecimiento, en los que el médico, por decisión propia y consciente, adquiera el compromiso de lograr u obtener un resultado específico, esto es, que se obligue para con el paciente a la consecución de un fin determinado, supuesto en el que, como es obvio entenderlo, la obligación a su cargo se tipifica como de resultado (Corte Suprema de Justicia, Sentencia del 05 de noviembre de 2013, M. P. Arturo Solarte Rodriguez).

En lo atinente a la cirugía estética, la sola intervención no implica que las obligaciones del galeno sean de resultado, sino que esto dependerá de la autonomía de la voluntad, lo cual explicó la Corte Suprema así:

Para el caso de la cirugía plástica con fines meramente estéticos, por lo tanto, puede darse el caso de que el médico se obligue a practicar la correspondiente intervención sin prometer o garantizar el resultado querido por el paciente o para el que ella, en teoría, está prevista; o de que el profesional, por el contrario, sí garantice o asegure la consecución de ese objetivo (Corte Suprema de Justicia, Sentencia del 05 de noviembre de 2013, M. P. Arturo Solarte Rodriguez).

En este orden de ideas, la sola intervención del cirujano estético no permite inferir -según lo plantea la Corte- que la obligación pactada sea de resultado, orientada a alcanzar un objetivo específico. Quiere decir ello que, aun tratándose de cirugía estética, cobra relevancia el consentimiento vertido en el contrato, que al final determina el contorno de las obligaciones asumidas por el galeno, porque la naturaleza de la obligación es negociable, según lo expuesto por el alto tribunal.

La postura de la Corte corresponde con la de su homóloga española, la cual desde la sentencia del 29 de junio de 2007 (RJ $2007 \backslash 3871$ ) excluyó a la medicina de la categoría de las obligaciones de resultado, incluso cuando el procedimiento realizado es de carácter embellecedor, porque los médicos actúan sobre personas lo que implica que hay un elemento de aleatoriedad aun cuando el paciente no posee problemas de salud previos (Montalvo, 2013), inclusive algunos magistrados de esa Corte manifestaron que la noción de que las obligaciones de los médicos estéticos son de resultado ha pasado a la historia (Kvitko, 2011, p. 16). 
La tesis que plantea este artículo alude a que la posición de la Corte es riesgosa para los pacientes-consumidores, en la medida que da absoluta libertad a las partes para determinar la naturaleza de las obligaciones (medio o resultado) sin tomar en consideración la debilidad contractual del paciente que requiere los servicios estéticos, frente al profesional que maneja la información y los aspectos técnicos de los procedimientos quirúrgicos. Esta circunstancia, necesariamente, incide en los aspectos procesales, relacionados con la carga de la prueba de la culpa del galeno, la cual siempre estaría en cabeza del demandante, en caso de un daño acaecido con la intervención médica contratada.

Esta libertad contractual para determinar el contenido del contrato, en supuesta igualdad de condiciones - postura que no se comparte- contrasta con el ofrecimiento de servicios médicos atendiendo los parámetros del mercado y la posibilidad real del cirujano en influir para que la obligación sea de medio, a pesar de que el paciente busque un resultado específico orientado hacia el embellecimiento. Así las cosas, debe buscarse una solución normativa o interpretativa, más favorable para el paciente consumidor, atendiendo a que en clave de relación de consumo, es el contratante débil, cuya posición en el momento de la realización del contrato respectivo es de total asimetría. En consideración a ello, para casos como estos, deben existir restricciones a la autonomía de la voluntad, relacionados con los acuerdos especiales de las partes, orientados a consentir pactos o cláusulas desfavorables al paciente-consumidor que refuercen justamente esta asimetría y que puedan incidir en la naturaleza jurídica de las obligaciones contratadas y su correlato en la carga de la prueba.

\section{LA CIRUGÍA ESTÉTICA EN COLOMBIA COMO PRODUCTO DE CONSUMO}

En este acápite se demostrará que las cirugías estéticas deben ser consideradas como producto de consumo. Como punto de partida ha de tenerse en cuenta el auge en la práctica de las cirugías estéticas, cuyo fin no es curativo. De hecho, los consumidores de este tipo de servicios buscan un determinado estándar de belleza creado por el mercado, patrón que en hombres y mujeres puede ser incorporado a través de la cirugía estética bajo la promesa inclusive de alcanzar un mejor nivel de vida en un asociacionismo conveniente con discursos mediáticos relativos a las formas del cuerpo; por ello sostiene Herrera (2012) que:

[E]n la cirugía estética se entrelazan el cuerpo biológico -el individuo-y el cuerpo social -sociedad-, por lo tanto, se moldea o se re-construye el cuerpo biológico a partir de las demandas del cuerpo social.

La cirugía estética está redefiniendo la forma cómo debe lucir el cuerpo del hombre y de la mujer. Apoyado por las publicidades y los medios de comunicación se crea un ideal de belleza difícil de alcanzar. De este modo, se promociona a la cirugía estética como la solución para, por una parte, mejorar el aspecto 
del cuerpo y, por otra, mejorar el bienestar personal (Herrera, 2012, p. 9).

Entonces, ¿por qué tendría que caracterizarse la cirugía estética como relación de consumo? Esta es una respuesta que debe ser analizada con detenimiento, en el sentir de Herrera (2012) porque "a partir del siglo XX, comienza la mercantilización del cuerpo, en donde este se convierte en un objeto más de consumo. Dentro de la gama de productos que existen para embellecer el cuerpo se encuentra la cirugía estética que se ha convertido en otro bien de consumo" (p. 23).

A pesar de lo anterior, la decisión aludida en la sentencia de 5 de noviembre de 2013, de la Sala de Casación Civil de la Corte Suprema de Justicia, con ponencia del magistrado Arturo Solarte Rodríguez, concluyó que en la práctica de procedimientos médicos estéticos prima la autonomía de la voluntad para delimitar el al cance y contenido de las obligaciones del galeno, de tal suerte que las obligaciones, inclusive en la cirugía médica estética, pueden ser de medio o de resultado conforme lo acuerden las partes. El asunto objeto de pronunciamiento era relativo a una controversia entre una paciente y su cirujano estético, por las consecuencias de un "lifting facial" o "rejuvenecimiento".

En esta decisión la Corte estimó que es carga del demandante acreditar que el médico se obligó a un resultado específico, y en su ausencia se reputa que la obligación contraída por el profesional es solo de medio; por lo tanto, le correspon- de a la demandante la carga de probar los elementos fundantes de la responsabilidad, y al médico cirujano solo la prueba de la diligencia y cuidado según la lex artis ad hoc.

La decisión en comento posee aclaración de voto del magistrado Ariel Salazar Ramírez, quien afirma que la cirugía plástica lleva ínsita una obligación de resultado, al tener en cuenta los avances de la medicina y el saber experto, que demandan del cirujano estético una prestación específica y no los cuidados solícitos de forma indeterminada (relación regular); tal opinión por su relevancia se transcribe literalmente:

La vida, la salud, la integridad física y moral, no son simples mercancías sino bienes personalísimos sumamente preciados que gozan de protección constitucional y civil, y por ello los médicos no pueden tratar a sus pacientes de manera irresponsable o sin comprometerse a obtener el resultado previsto por los estándares del oficio, ni siquiera en el caso de que manifiesten expresamente que no garantizan el producto de su labor; sobre todo cuando la reputación del galeno no precede a su eficacia, como ocurría en épocas pretéritas, sino que su prestigio se tasa actualmente por los aciertos que obtiene en cada caso que atiende, los cuales son medidos con rigor por el cliente, por la comunidad científica y por la sociedad en general (Aclaración de voto, Corte Suprema de Justicia, Sala Civil, Sentencia de 5 de noviembre de 2013). 
En concordancia con la anterior opinión, se considera que la relación del cirujano estético con su paciente no se desarrolla bajo parámetros indefinidos en la prestación; tal es el compromiso del médico con el resultado, que en ocasiones la tecnología posibilita simular el resultado probable de la cirugía (Jaramillo, 2011, p.380). Además, no resulta coherente con la realidad que una persona se someta a un procedimiento quirúrgico estético, sin que se le garantice el resultado embellecedor pactado; de hecho los fines cosméticos son la causa que determina el consentimiento del paciente.

En consecuencia, se debe determinar si es de la naturaleza del pacto médico estético el hecho de que la obligación del médico sea de medio o de resultado. La posición que se sustenta es que en este tipo de negocios jurídicos, por naturaleza, las obligaciones son de resultado. De hecho, cobra especial significación la información clara, oportuna y suficiente suministrada por el galeno, puesto que esta determina el consentimiento del paciente contratante en torno a ciertas expectativas cosméticas. Luego, es medular en la prestación de estos servicios el resultado al que se comprometió el galeno, pues, cada cuerpo reacciona de formas distintas a las intervenciones quirúrgicas y será obligación del médico determinar qué resultados se pueden obtener de un procedimiento para cada persona, en lugar de permitir que de manera indeterminada el médico solo se comprometa a la realización del procedimiento. Las anteriores proposiciones determinan el marco de las consecuencias que se estima provienen de considerar la cirugía estética como una relación de consumo.

En el mismo orden de ideas, al remitirnos al Estatuto del Consumidor, el numeral 3. del artículo 5 de la Ley 1480 de 2011, considera que, consumidor es "toda persona natural o jurídica que, como destinatario final, adquiera, disfrute o utilice un determinado producto, cualquiera que sea su naturaleza para la satisfacción de una necesidad propia, privada, familiar o doméstica y empresarial cuando no esté ligada intrínsecamente a su actividad económica"; así las cosas, el paciente es una persona natural que satisface una necesidad privada y propia. Se estima, además, que es una relación de consumo: porque el acceso al servicio está delimitado por relaciones de mercado, los cirujanos estéticos ofrecen sus servicios a través de medios publicitarios, se prescinde en las pautas de las consecuencias médicas adversas de los procedimientos y se aducen únicamente los beneficios de los mismos. No es exacto establecer que los cirujanos estéticos ofertan sus servicios dentro de los parámetros generales de la medicina pues siempre los centros de atención, más que instituciones de salud, se perciben como "spas" y se ofertan servicios de belleza distintos a los procedimientos médicos, por lo que los tratamientos estéticos son escindibles respecto a la mayoría de servicios médicos.

Existen opiniones en la doctrina que consideran que la prestación de servicios médicos de ninguna manera puede ser objeto de las obligaciones de los consu- 
midores (Forero, 2014, p. 88); sin embargo, tal comparación se limita el Sistema General de Seguridad Social en Salud y como ya se vio las cirugías estéticas no se practican en este contexto, sino en el de la relación privada del médico con su paciente, y las demás disertaciones no cuentan con un soporte argumentativo que permita darles mérito a esas conclusiones.

Por su parte, Tamayo (2013) sostiene que los servicios médicos quedan bajo la regulación del Estatuto de Consumidor, aun cuando no sea de su gusto este tipo de soluciones; sin embargo, considera que ante la falta de claridad relativa al tema, se debió "haber consagrado para ellos un régimen probatorio especial, claro y apropiado" (p. 19). Sobre el particular el mismo autor plantea que "en materia médica hay muchas obligaciones que son de medio, y muchas otras que son de resultado, pero sin que se trate de soluciones pacíficas" (p.18).

Además, en el Decreto 3466 de 1982, que regulaba las relaciones de consumo, se excluyó de su marco de aplicación a las profesiones liberales de forma expresa en el artículo 45, mientras que la Ley 1480 de 2011 no tiene norma equivalente, lo cual muestra un interés tácito del legislador de no excluir del resorte de la norma de consumo a las profesiones liberales -como la medicina-.

Por otro lado, las obligaciones de medio también pueden ser objeto de protección por el Estatuto de Consumidor (artículo 7 L. 1480/2011), por lo que una exclusión de plano, aun si se tiene como presupuesto que la obligación del médico-estético es de medio, no encuentra asidero normativo (Giraldo, 2013).

Es preciso señalar que la normativa de protección al consumidor se erigió con el fin de que se restaure la simetría en la relación jurídica del consumidor con su proveedor (del bien o el servicio). La debilidad del consumidor se justifica porque el mercado crea la necesidad de la demanda a través de procesos económicos organizados en subsistemas empresariales, inclusive como clústeres de negocios, desde los cuales se ofrecen bienes y servicios de manera habitual, además existe una cadena de productores y proveedores que poseen mayor información sobre los bienes y servicios ofrecidos (Iturraspe y Lorenzetti, 1993, p. 54). A ello ha de agregarse el conocimiento técnico del profesional, que supera con creces el conocimiento del pacienteconsumidor.

En este orden de ideas, el Estatuto del Consumidor es aplicable en la responsabilidad médica inclusive cuando la obligación es de medio. Sin embargo, como se verá, la determinación de la naturaleza de la obligación -de medio o resultado-en la cirugía estética no puede estar al arbitrio de las partes (tomando en consideración la debilidad de una de ellas), porque la implicación directa sería la modificación de la carga de la prueba en la medida que por pactos especiales (art.1604, inciso final) podría modificarse el régimen general de la prueba de la culpa. 


\section{LA CIRUgÍA ESTÉTICA EN COLOMBIA Y SUS EFECTOS EN EL MARCO DE UNA RELACIÓN DE CONSUMO}

Luego de haber analizado el marco normativo y teórico en el cual se enmarca la pregunta problema y de haber dado argumentos que permiten caracterizar la cirugía estética como relación de consumo, como último punto se examinarán los efectos y alcances de esta postura.

Como se comentó con anterioridad, la Corte se inclina por permitir la libertad contractual entre cirujano estético y paciente, pues considera tácitamente que el paciente contrata en pie de igualdad con aquel; por ello tiene la libertad de negociar los términos de la intervención, fijando los límites y el alcance del acto médico de común acuerdo con el cirujano, definiendo inclusive si las obligaciones son de medio o de resultado (deberes primarios).

Esa tesis no posee un cuerpo argumentativo fuerte, en primera medida, porque la naturaleza de una obligación no se altera según la intención de las partes, sino que la naturaleza jurídica de la misma determina su carácter; para el caso en comento ayuda el contexto de celebración del contrato de cirugía estética y los fines que se persiguen. Luego, el contenido prestacional necesariamente es mediado por la naturaleza jurídica de la obligación a cargo del acreedor y es esta la que es de medio o de resultado. En esa línea argumental lo señaló el magistrado Ariel Salazar, en la aclaración de voto de la sentencia antes comentada, en los siguientes términos:
La naturaleza de la prestación, que coincide con el fin que se propusieron las partes al contratar, no es entonces una cuestión accesoria que sólo "en algunos eventos particulares" determine la clase de obligación de que se trata, sino que es un atributo o elemento inherente de éstas: es lo primario y decisivo que llena de contenido y significación la relación obligatoria y precisa el carácter típico de la misma; $\mathrm{y}$, como tal, constituye el presupuesto esencial para su interpretación, como lo manda la norma[... . Las anteriores reflexiones, aplicadas al sub lite, conllevan a aceptar que más allá de lo que las partes hayan estipulado 'de modo expreso', es la naturaleza misma de la obligación, según los estándares o usos de la actividad que es objeto del convenio, lo que permitirá dirimir la disputa central de si la obligación es de medios o de resultados (Aclaración de voto, Corte Suprema de Justicia, Sala Civil, Sentencia de 5 de noviembre de 2013).

Ahora bien, el efecto práctico de un pacto o acuerdo que modifique el carácter de una obligación es el de invertir la carga de la prueba en la relación contractual y obligar al acreedor (paciente) a demostrar la culpa del deudor (el cirujano). Sin embargo, las modificaciones en la carga de la prueba que sean en desmedro del deudor se pueden encuadrar en la categoría de cláusulas abusivas, según lo dispuesto en el numeral 3. ${ }^{\circ}$ del artículo 43 del Estatuto del Consumidor.

Por lo tanto, si se tiene que la relación entre el cirujano estético y su paciente es 
de consumo, la consecuencia del cambio de la naturaleza de la obligación y, por ende, de la carga de la prueba tendría como sanción para la cláusula pactada, su ineficacia de pleno derecho; empero, "no se afectará la totalidad del contrato, en la medida que este pueda subsistir sin las cláusulas nulas o ineficaces" (art.44 L. 1480/2011).

Es decir, la libertad contractual esgrimida por la Corte Suprema de Justicia para modificar la naturaleza de las obligaciones en los contratos de cirugía estética no es tal, si se tiene como presupuesto que este tipo de relaciones son de consumo y como ya se explicó, no existe norma que permita arribar a una conclusión distinta porque cuando la ley no distingue, no le es dado al intérprete distinguir.

Así las cosas, si la naturaleza jurídica de la obligación es de resultado, no pueden las partes pactarlas como de medio; empero, en el caso contrario sí procedería, porque la limitante existe cuando la modificación de la carga de la prueba es en desmedro del consumidor y en este último caso sería favorable a él.

Por otro lado, para definir el contenido prestacional como de resultado, debe acudirse a los antecedentes, para lo cual se deben tener en cuenta las citas médicas previas, que en muchas de las ocasiones consisten en animaciones digitales de los resultados estimados (Jaramillo, 2011), o fotografías con las respectivas marcas trazadas por el cirujano estético en el cuerpo del paciente. Así las cosas, resulta extraño que luego de una consulta en donde precisamente se consintió sobre la base de los resultados cosméticos, una vez verificado el procedimiento estético, el galeno alegue que este solo se había comprometido a prestar los cuidados concienzudos, solícitos y conformes con los datos adquiridos por la ciencia, precisamente porque la intención del paciente fue determinada por los resultados y por ello consintió. De hecho sostiene la Corte que si las obligaciones "son de resultado, por así haberse pactado expresamente, habrá cumplimiento cuando el acreedor obtiene las expectativas creadas"'. No puede entonces con posterioridad aducir el cirujano que solo es responsable por el cumplimiento de la lex artis y que en consecuencia la frustración del resultado no es su responsabilidad, más cuando el mismo comprometió su responsabilidad profesional apoyado en simulaciones digitales.

Cabe entonces señalar la relevancia de la obligación de información contenida en el artículo 23 de la Ley 1480 de 2011, en lo relativo a los términos de la intervención y el resultado esperado de la misma. Porque como lo sostiene la aclaración de voto de la sentencia de 5 de noviembre de 2013, "los estándares de esa clase de intervenciones muestran que la persona, estando bien de salud, persigue un embellecimiento corporal". Por lo tanto, el que esta relación sea de consumo conlleva que la obligación de información del galeno respecto al contenido de la prestación es mucho más específica.

Corte Suprema de Justicia, Sentencia de 24 de mayo de 2017, M. P. Luis Armando Toloza Villabona. 
De igual manera, el derecho a la información no se limita a una advertencia general de peligro, sino que el médico, en orden de cumplir con el requisito del consentimiento informado, debe en cada caso señalar los riesgos específicos de cada procedimiento, como ha sido expuesto por la Sala de Casación Civil de la Corte Suprema de Justicia². En consecuencia, en los casos de procedimientos médicoestéticos, debería incluir la posibilidad real de la obtención del resultado pactado con el procedimiento estético, por la expectativa que genera para el paciente y ser el motivo por el que brindó su consentimiento. "De esa manera, si el galeno fija un objetivo específico, cual ocurre con intervenciones estéticas, esto es, en un cuerpo sano, sin desconocer su grado de aleatoriedad, así sea mínimo o exiguo, se entiende que todo lo tiene bajo su control y por ello cumplirá pagando la prestación prometida"3.

En el caso de resultados que no se pueden obtener debido a condiciones del cuerpo del paciente, si tal condición no fue advertida en el momento de pedirse el consentimiento informado y esa imposibilidad era conocida por el facultativo o por lo menos debía serlo por su conocimiento experto, las consecuencias adversas de la misma le son imputables. La omisión del deber de informar y obtener el consentimiento informado -sostiene la Cortehace responsable al galeno, no solo por la conculcación de la dignidad humana,

2 Sentencia de 30 de agosto de 2011, M. P. William Namén Vargas.

3 Así lo sostiene la Corte en la aludida Sentencia de mayo de 2017. sino por los daños patrimoniales y extrapatrimoniales por las intervenciones no autorizadas ni consentidas.

Si bien la obligación de informar no ha sido estudiada por la jurisprudencia con relación a la cirugía estética, esta deviene de una interpretación armónica de la naturaleza de la obligación del galeno y el deber de informar de los proveedores de productos de consumo; lo que sí ha dicho la jurisprudencia es que la omisión de alguna de las obligaciones respecto a la historia médica -en este caso, el anexo consentimiento informado- acarrea para el facultativo consecuencias jurídicas, de hecho,

[L]a obligación de informar y obtener el consentimiento informado, hace responsable al médico, y por consiguiente, a las instituciones prestadoras del servicio de salud, obligadas legalmente a verificar su estricta observancia, no sólo del quebranto a los derechos fundamentales del libre desarrollo de la personalidad, dignidad y libertad, sino de los daños patrimoniales y extrapatrimoniales causados a la persona en su vida, salud e integridad sicofísica a consecuencia del tratamiento o intervención no autorizado ni consentido dentro de los parámetros legales[...]su elaboración [la de la historia clínica] en forma es una obligación imperativa del profesional e instituciones prestadoras del servicio, y su omisión u observancia defectuosa, irregular e incompleta, entraña importantes consecuencias, no sólo en el ámbito disciplinario sino en los procesos judiciales, en 
especial, de responsabilidad civil, por constituir incumplimiento de una obligación legal integrante de la respectiva relación jurídica (Corte Suprema de Justicia, Sentencia de 30 de agosto de 2011, M. P. William Namen Vargas).

No es entonces gratuito que se circunscriba la relación cirujano estético-paciente al régimen del consumidor. El paciente debe tener claridad respecto del procedimiento estético, para que pueda tomar su decisión de manera libre e informada. Lo anterior redunda en mayor seguridad jurídica al momento de presentarse conflictos, pues los elementos del contenido de la prestación se encuentran delimitados por el consentimiento informado; entonces el paciente conocería el alcance específico del procedimiento, y el médico, el parámetro para la valoración de su responsabilidad. Así las cosas, prometer un resultado imposible y no haber cumplido el deber de informar no lo releva del pago de la indemnización por el incumplimiento del deber legal.

Como se ha venido planteando, las soluciones en la materia no son pacíficas, pero urgen propuestas normativas e interpretativas que garanticen la salud de los usuarios de este tipo de procedimientos. Sin embargo, es factible que el paciente se vea afectado porque: (i) el procedimiento produce un daño o, (ii) no se obtiene el resultado deseado. En el primer caso, se aplica el régimen de la prestación de un servicio médico estético defectuoso; en tales eventos el defecto del servicio o eventualmente de un bien, aunado a la prueba del daño, como consecuencia de ese producto defectuoso (nexo causal), hace nacer "en cabeza del productor o expendedor la responsabilidad por producto defectuoso" (Giraldo, 2013, p. 29), prescindiéndose del elemento culpa, e invirtiendo la carga de la prueba hacia el médico, quien deberá probar la causa extraña, de conformidad con el artículo 22 de la Ley 1480 de 2011. En el segundo, podría pedirse el cumplimiento de la garantía legal, es decir, el paciente está facultado para solicitar la prestación del servicio en las condiciones pactadas (calidad, seguridad e idoneidad) o a la devolución del dinero según lo establecido en el numeral 3 del artículo 11 del Estatuto del Consumidor.

Por último, la aplicabilidad del Decreto 735 de 2013 "Por el cual se reglamenta la efectividad de la garantía prevista en los artículos 7 y siguientes de la Ley 1480 de 2011" alude en gran medida a la garantía sobre bienes y no en la prestación de servicios, facultando al consumidor a escoger entre la repetición del servicio o la devolución del dinero (artículo 16), lo cual es una consecuencia obvia del incumplimiento obligacional de la prestación de servicios y se encuentra contemplado expresamente en el Estatuto del Consumidor.

\section{CONCLUSIONES}

La sociedad capitalista promueve disímiles formas de consumo de bienes y servicios que desbordaron las tradicionales teorías economicistas del consumo racional. Una de estas novedades está representada en el consumo de cirugías 
plásticas para la satisfacción de los consumidores de la industria de la salud.

Hoy es posible caracterizar la cirugía estética como relación de consumo, pues el paciente-consumidor es destinatario final del servicio orientado a la satisfacción de una necesidad propia, circunstancia que implica una postura distinta de la tradicional, en la cual el ejercicio de la medicina implicaba el consentimiento del médico y del paciente, expresado en el marco de un contrato bilateral, consensual, oneroso, y conmutativo, configurando una obligación de medios por parte del galeno, lo que tenía como consecuencia que la responsabilidad debía ser examinada bajo los parámetros de la responsabilidad subjetiva, según el régimen común del Código Civil, excepto que el galeno se obligara a un resultado específico de manera expresa. En estos casos particulares la obligación se tornaba de resultado, lo que invertía la carga de la prueba.

La Ley 1480 de 2011, cuerpo normativo que desarrolla el art. 78 Constitucional y actualiza el régimen de protección de los consumidores, determina el alcance de las obligaciones que se desprenden del contrato de servicios médicos estéticos entre particulares considerando los siguientes argumentos:

La Corte en diversas oportunidades ha reconocido la asimetría contractual del consumidor como consecuencia de la libertad de empresa y la masificación de los servicios médicos estéticos ofertados, aspecto que exige respuestas concretas del derecho, pues la relación del cirujano estético con su paciente se ve necesariamente mediada por la dinámica del mercado. Por otra parte, la norma no excluyó taxativamente el ejercicio de las profesiones liberales como sí lo hacía el Decreto 3466 de 1982, pudiendo ser aplicado dicho estatuto al ejercicio de la medicina. Por otra parte, el conocimiento del cirujano es experto, lo que introduce un desequilibrio contractual frente al paciente, por el manejo técnico del procedimiento e información relacionada con el mismo, que puede determinar el consentimiento para la firma del acuerdo, en condiciones desfavorables para el paciente. Así las cosas, de dicha consideración se pueden desprender las siguientes consecuencias: si no hay conformidad con la prestación del servicio, es posible exigir la garantía legal, para la prestación a satisfacción del servicio contratado o la devolución del dinero. Sin embargo, si una vez verificado el procedimiento, se concretó un daño, es factible iniciar una acción ordinaria, correspondiéndole al galeno exonerase, si prueba la existencia de una causa extraña y, por último, como una consecuencia importante de la asimetría contractual, la posibilidad de tener como ineficaces, las cláusulas contractuales modificatorias de la responsabilidad del cirujano, cuando de los antecedentes y del consentimiento informado puede desprenderse que la naturaleza de la obligación del galeno y el contenido prestacional de la misma se refiere a una obligación de resultado.

\section{REFERENCIAS}

Castillo, M., y Céspedes, E. (s. f.). Características del contrato médico, consultado el 20 de junio de 2016 recuperado de http://www. 
castillofreyre.com/archivos/pdfs/articulos/ caracteristicas de contrato medico.pdf

Congreso de la República de Colombia. Ley 1480 de 2011 "Por medio de la cual se expide el Estatuto del Consumidor y se dictan otras disposiciones".

Constitución Política de Colombia. (2016). Bogotá, Colombia: Editorial Leyer.

Corte Constitucional de Colombia. Sentencia T-661 de 22 de septiembre de 2009. M. P. de 2009: Nilson Pinilla Pinilla

Corte Suprema de Justicia. Sentencia del 30 de enero de 2001. M. P. José Fernando Ramírez Gómez.

Corte Suprema de Justicia. Sentencia del 22 de julio de 2010. M. P. Pedro Octavio Munar Cadena.

Corte Suprema de Justicia. Sentencia de 30 de agosto de 2011. M. P. William Namen Vargas.

Corte Suprema de Justicia. Sentencia del 05 de noviembre de 2013. M. P. Arturo Solarte Rodriguez.

Corte Suprema de Justicia. Sentencia del 30 de agosto de 2013 . M. P. Ruth Marina Díaz Rueda.

Corte Suprema de Justicia. Sentencia del 24 de mayo de 2017. M. P. Luis Armando Toloza Villabona.

Giraldo, L. F. (2013). Responsabilidad civil por la prestación del servicio médico, a la luz de la nueva regulación de protección al consumidor. Criterio Jurídico, Cali, Colombia 13 (1) 211-246.

Herrera, C. P. (2012). Cuerpos en re-construcción: el consumo de cirugía estética en la ciudad de Ambato. Sede Quito, Ecuador: Flacso.

International Society of Aesthetic Plastic Surgery (Isaps). (2017). The International study on aesthetic/cosmetic procedures performed in 2016, consultado el 2 de noviembre de 2017 recuperado de https://www.isaps.org/ wp-content/uploads/2017/10/GlobalStatistics2016-1.pdf

Iturraspe, J. M., y Lorenzetti, R. L. (1993). Defensa del consumidor. Buenos Aires, Argentina: Rubinzal-Culzoni Editores.
Jaramillo, C. I. (2010). La culpa y la carga de la prueba en el campo de la responsabilidad médica. Bogotá, Colombia: Editorial Ibáñez.

Jaramillo, C. I. (2011). Responsabilidad Civil Médica: la relación médico-paciente. Bogotá, Colombia: Editorial Ibáñez y Pontificia Universidad Javeriana.

Kvitko, L. A. (2011). La responsabilidad médica en cirugía estética. ¿Obligación de medios o de resultados? Antecedentes. Jurisprudencia Argentina y Española. Cambio radical en la doctrina y el criterio jurisprudencial español. Medicina Legal de Costa Rica, 28(1), 7-24.

Lorenzetti, R. L. (1997). Responsabilidad civil de los médico. Tomo I. Buenos Aires, Argentina: Rubinzal Editors.

Montalvo , P. (2013). Análisis de la postura de nuestros tribunales ante los pleitos relacionados con cirugía plástica y estética. Revista Cesco de Derecho de Consumo, 200(8), 196-208.

Pérez Forero, A. C. (2014). El Estatuto del Consumidor y la prestación de servicios de salud. Prolegómenos, 17(34), 78-95.

Presidencia de la República de Colombia. Decreto 735 de abril de 2013, "Por el cual se reglamenta la efectividad de la garantía prevista en los artículos $7 .^{\circ}$ y siguientes de la Ley 1480 de 2011.

Proexport Colombia. (2013). Oportunidades del sector salud en Colombia, consultado el 02 de marzo de 2016 recuperado de http:// www.procolombia.co/sites/default/files/sector_salud en colombia_2013-10-08. $\underline{\mathrm{pdf}}$

República de Argentina. Ley 26.361 Modificacatoria de la Ley N. 24.240 .

Superintendencia de Industria y Comercio(SIC). Concepto 13-101665-00001-0000-00 de 2013.

Tamayo, J. (2013). La responsabilidad civil en el nuevo estatuto del consumidor. Bogotá, Colombia: Universidad Jorge Tadeo Lozano.

Villalba, J. C. (2009). Aspectos introductorios al derecho del consumo. Prolegómenos, 12(24), 77-95. 